\title{
Cutting parameters effects on the machining of two high density polyethylene pipes resins
}

\section{Cutting parameters effects on HDPE machining}

\author{
Mounia Kaddeche ${ }^{1, a}$, Kamel Chaoui ${ }^{2}$ and Mohamed Athmane Yallese ${ }^{3}$ \\ ${ }^{1}$ Laboratoire de Recherche Mécanique des Matériaux et Maintenance Industrielle (LR3MI of UBM Annaba), \\ Mechanical Engineering Department, 8 May 1945 University of Guelma, PO Box 401, Guelma 24000, Algeria \\ 2 Laboratoire de Recherche Mécanique des Matériaux et Maintenance Industrielle (LR3MI), Mechanical Engineering \\ Department, Badji Mokhtar University of Annaba, PO Box 12, Annaba 23000, Algeria \\ 3 Laboratoire de Mécanique et des Structures (LMS), Mechanical Engineering Department, 8 May 1945 University \\ of Guelma, PO Box 401, Guelma 24000, Algeria
}

\author{
Received 20 January 2012, Accepted 2 October 2012
}

\begin{abstract}
The market demand for machining and cutting of various plastics parts is in continuous increase. The aim of this study is to extract prediction laws for surface roughness, cutting forces and temperatures evolution during the machining of two polyethylene pipes grades (HDPE-100) and (HDPE-80). It was found that feed rate is the most prevailing factor on roughness criteria and that better surfaces are obtained during the machining of the harder HDPE-80 resin. Also, cutting speed improved surface quality for speeds up to $200 \mathrm{~m} \cdot \mathrm{min}^{-1}$ but the rising interface temperature caused surface damage and material rapid softening. Also, feed exponents, in mathematical models, were found to be 3 to 4 times higher than those of cutting speed and depth of cut. An increase in the cutting speed led to a gradual reduction for the 3 cutting forces components $(F r, F a$ and $F v)$ with a dominance of the tangential force $(F v)$. As expected, the value of the depth of cut had a large influence on the temperature within the cutting zone. This temperature is slightly higher during the machining of HDPE-80 compared to that of HDPE-100 most probably because of hardness differences. The analysis of variance (ANOVA) was performed to check the adequacy of the mathematical models relating cutting parameters with roughness, cutting forces and global cutting zone temperature.
\end{abstract}

Key words: Polyethylene pipe / machining / cutting parameters / surface roughness / cutting forces / ANOVA / mathematical models

\section{Introduction}

Polymeric parts and fittings are mostly produced by moulding and extrusion processes, but for small series or complicated shapes, machining becomes necessary if not unavoidable. Nowadays, it is established that machining characteristics of polymers and composites depend primarily on their mechanical, heat transfer and rheological properties [1]. Their mechanical coupling and/or amorphous modulus are significantly different as compared with all other materials. Consequently, any evaluation of machining characteristics in the case of polymers and specifically semi-crystalline ones must consider the particular properties of the material being used and the selected service environment [2-8]. In general, most of the data available on tooling and cutting parameters for plastics are built on practical experiences based on machining

\footnotetext{
${ }^{a}$ Corresponding author: m_kaddeche@yahoo.fr
}

of metallic materials. Since metals are considerably hard and tough enough compared to plastics, commonly little modifications are worked out on tooling and equipment to outfit safely the specific physical characteristics of plastics [2]. Polymers present a complex nonlinear mechanical behavior which is function of structural morphology and external applied factors. Basically, polymers are classified by taking into account three basic characteristics (density, molecular weight, and molecular weight distribution) that significantly influence the manufacturing processes and the end-use properties; this is known as the structureproperty-relationship [1, 2, 7-9].

The machining of polymeric materials, by chips removal, must take into account manufacturing conditions, material characteristics, applied stresses and the usage environment, as well as the interactions between these various criteria especially in terms of heat generation. Gombette and Ernoult indicated that the voluminal thermal 


\section{Nomenclature}

\begin{tabular}{|c|c|}
\hline$a p$ & depth of cut $(\mathrm{mm})$ \\
\hline$C_{1}, C_{2}$ & constants \\
\hline$e$ & exponential function \\
\hline$f$ & feed rate $\left(\mathrm{mm} \cdot \mathrm{rev}^{-1}\right)$ \\
\hline$F a$ & axial force $(\mathrm{N})$ \\
\hline $\mathrm{Fr}$ & radial force $(\mathrm{N})$ \\
\hline$F v$ & tangential force $(\mathrm{N})$ \\
\hline$K_{I C}$ & fracture toughness $\left(\mathrm{MPa} \cdot \mathrm{m}^{1 / 2}\right)$ \\
\hline$R^{2}$ & determination coefficient \\
\hline$R a$ & arithmetic mean roughness $(\mu \mathrm{m})$ \\
\hline Rt & total roughness $(\mu \mathrm{m})$ \\
\hline$R z$ & mean depth of roughness $(\mu \mathrm{m})$ \\
\hline$r_{\varepsilon}$ & tool nozzle radius $(\mathrm{mm})$ \\
\hline$t^{\circ}$ & $\begin{array}{l}\text { temperature in the vicinity } \\
\text { of the cutting zone }\left({ }^{\circ} \mathrm{C}\right)\end{array}$ \\
\hline$T_{\mathrm{g}}$ & glass transition temperature $(\mathrm{K})$ \\
\hline$V c$ & cutting speed $\left(\mathrm{m} \cdot \mathrm{min}^{-1}\right)$ \\
\hline$x_{1}, x_{2}, x_{3}$ & power constants related to roughness \\
\hline$y_{1}, y_{2}, y_{3}$ & power constants related to cutting forces \\
\hline \multicolumn{2}{|r|}{ Greek symbols } \\
\hline$\alpha$ & clearance angle $\left(^{\circ}\right)$ \\
\hline$\chi r$ & cutting edge angle $\left({ }^{\circ}\right)$ \\
\hline$\gamma$ & rake angle $\left({ }^{\circ}\right)$ \\
\hline$\Delta$ & model accuracy (\%) \\
\hline
\end{tabular}

dilation coefficients of polymers are large compared to those of metals or of covalent materials which is expected and might be a handicap to several applications involving friction and thus heat generation [2]. In addition, they are also bad heat conductors with low melting points. The combination of these two characteristics shows that the heat generated by machining operation remains concentrated into the machined zone and leads to important thermal stresses which instigate thermal risks of degradation $[3,4]$.

The quality of machined surfaces is influenced by various parameters, including cutting parameters (cutting speed: $V c$, feed rate: $f$ and depth of cut: $a p)[3,4,10]$. The influence of tool design and machining conditions such as rake angle, tool tip radius, depth of cut and cutting speed on surface roughness, chip formation, tool wear, gumming and burning of polymeric materials has been investigated by several researchers $[3,4,11]$. It was concluded that rake angle $[3,4]$ and transverse feed rate [11] are significant parameters that determine the surface roughness in polymer machining. In addition to the above processing variables, the effect of physical and chemical properties of polymeric materials is much more pronounced during machining operations. Because of their visco-elastic behaviour, it is complicated to reveal the relationship between machinability and material properties compared to the wellestablished behaviour of polycrystalline steels [11].

Xiao and Zhang tried to evaluate the machinability of typical thermoplastic and thermosetting polymers and to understand the effect of their viscous properties on surface integrity, chip formation and machining forces [9]. The interaction between the strain rate and temperature during machining was particularly studied and it was found that the viscous deformation of a polymer plays a decisive role in determining the quality of a machined surface. To minimize the surface roughness, for instance, the machining conditions must be selected in such a way that material removal should not create visco-plastic brittle cracking or tearing. The optimal machining condition must be based on the polymer properties, such as glass transition temperature $\left(T_{\mathrm{g}}\right)$, fracture toughness $\left(K_{I C}\right)$ and molecular mobility.

A number of studies on polymer machining [9] initiated investigations on the relationship of the material parameters, such as glass transition temperature, melting temperature, viscous effects and relaxation, with specimen surface finish [3,5,6,9-11]. For instance, E. F. Smith considered the effect of the glass transition temperature $\left(T_{\mathrm{g}}\right)$ on the surface quality of amorphous thermoplastic specimens subjected to single-point turning, and claimed that the glass transition temperature of a polymer is the most important property that governs the surface roughness [5]. If the temperature in the cutting zone exceeds $T_{\mathrm{g}}$, a good surface finish can be achieved and the material would be removed in a ductile manner; otherwise, a coarse surface appears because the material would have experienced a brittle fracture process increasing surface roughness. In 1993, Carr and Feger presented an exhaustive study of the effect of material properties on the surface roughness of several polymers with different $T_{\mathrm{g}}$ values and molecular weights, when subjected to single-point diamond machining [6]. They analyzed the relationship between the minimum polymer roughness and the tool speed based on the time-temperature superposition principle, and found that the surface roughness would decrease initially when the tool speed is increased because of a limited transition towards a ductile fracture mechanism. A further increase in cutting speed leads to a high deformation rate to which the polymer is unable to react. Thus, material flow (chip formation) is interrupted and fracture takes place [6].

It is always desirable to obtain a continuous chip to reduce both heat generation and deformation of the work material during cutting. To accomplish this, it is desirable to use tools having a critical rake angle, or larger rake angle, which produces continuous chips and minimum deformation. Cutting conditions selection is also essential; specifically the tooth cut thickness as determined by the feed rate. Cutting conditions which maximize the cut thickness must be selected, in order to decrease the generated heat because of friction phenomenon $[1,11]$. The results quoted by Vickerstaff and Gindy when cutting polycarbonate using HSS tools are representative of the cutting of most thermoplastics. Results confirmed the following observations: as the rake angle increases from negative to positive values, the cutting forces are reduced and simultaneously the direction of the cutting force components changes from downwards to upwards [12].

Among polymers, polyethylene (PE) has been one of the most extensively studied materials in polymer science, primarily as a consequence of its structural simplicity and its wide applicability. In particular, there is considerable 
Table 1. Mechanical properties of commercial HDPE-80 and HDPE-100 pipe resins.

\begin{tabular}{ccc}
\hline Mechanical properties & HDPE 80 & HDPE 100 \\
\hline Density at $+23{ }^{\circ} \mathrm{C}\left(\mathrm{kg} \cdot \mathrm{m}^{-3}\right)$ & 954 & 958 \\
Viscosity $\left(\mathrm{cm}^{3} \cdot \mathrm{g}^{-1}\right)$ & 320 & $\geq 360$ \\
Yield strength à $23{ }^{\circ} \mathrm{C}(\mathrm{MPa})$ & 22 & 23 \\
Yield elongation à $23{ }^{\circ} \mathrm{C}(\%)$ & 8 & 9 \\
Ultimate elongation $(\%)$ & $\geq 350$ & $\geq 350$ \\
Modulus of tensile elasticity at $23{ }^{\circ} \mathrm{C}(\mathrm{MPa})$ & 850 & 900 \\
Modulus of bending elasticity, $(\mathrm{MPa})$ & 1000 & 1200 \\
Hardness SHORE D $\quad\left\{\begin{array}{l}\text { at } 0{ }^{\circ} \mathrm{C} \\
\text { at } 20{ }^{\circ} \mathrm{C}\end{array}\right.$ & 67 & 63 \\
at $40{ }^{\circ} \mathrm{C}$ & 59 & 59 \\
at $60{ }^{\circ} \mathrm{C}$ & 53 & 54 \\
at $80{ }^{\circ} \mathrm{C}$ & 49 & 52 \\
Min. Required Strength, (MPa) & 8 & $>10$ \\
Slow Crack Growth resistance & $>3000$ & $>1000$ \\
Rapid Crack Propagation resistance, (bar) & $\geq 5$ & $\geq 25$ \\
\hline
\end{tabular}

interest in the mechanical creep behavior of PE because of its increasing use in engineering applications such as pipes for transmission and distribution of water and natural gas $[13,14]$. High density polyethylene (HDPE) pipes have been widely used in recent urban networks for water conveyance due to their advantages in terms of setting up, joining, toxicological safety and service lifetime [15-18]. Due to the nature of polymeric materials, polyethylene with excellent short-term mechanical strength can have poor long-term performance due to environmental stress cracking [14-16]. Manufacturing techniques do affect the mechanical behavior of HDPE in terms of elastic modulus, tensile strength and residual stresses [7, 17, 19-21].

The objective of this study is to establish prediction laws for surface roughness, cutting pressures and temperatures during the machining of two grades of polyethylene (HDPE-100 and HDPE-80) extruded pipes based on experimental tests. Firstly, a roughness study is conducted on the machined specimens according to a selected standard cutting regime. Furthermore, the cutting forces changes and temperature evolution are investigated. Finally, an analysis of variance (ANOVA) is performed to check the adequacy of the mathematical correlation models.

\section{Experimental approach}

The material used in this study was extruded by STPM CHIALI Co. of Sidi Bel-Abbès (Algeria). It was supplied in the form of pipes which are intended for the distribution of natural gas. The HDPE resin was obtained by addition polymerization, whereas the tubes were obtained by co-extrusion. Typical properties of HDPE-100 and HDPE-80 polymers are provided in Table 1 [18]. The experimental tests following standard orthogonal table L9 $(3)^{3}$ were performed on two HDPE pipes $400 \mathrm{~mm}$ length each [20-22]. The HDPE-100 pipe had an outside diameter of $200 \mathrm{~mm}$ whereas the HDPE- 80 had an outside diameter of $125 \mathrm{~mm}$. Pipe manufacturing standards impose for larger diameter to require resistant resins (HDPE-100+).

A TOS Trencin lathe $(6.6 \mathrm{~kW})$, Type SN40, was used for the turning operations (Fig. 1). Tests were performed without any lubrication in order to avoid material damage. Insert cutting tool is made of GC3015 (ISO: K10), with a nozzle radius $r_{\varepsilon}=0.8 \mathrm{~mm}$ and was manufactured by Sandvik. Tool holders are codified as CSBPR2525M12 with a common active part tool geometry described by: $\chi_{r}=+75^{\circ} ; \alpha=+5^{\circ}$; and $\gamma=7^{\circ}$. A fitted wooden mandrel was used to support pipe specimens onto the lathe and to provide adequate system rigidity.

Instantaneous roughness criteria measurements ( $R a$, $R t$, and $R z$ ) for each cutting condition were obtained with a Surftest 301 Mitutoyo roughness meter coupled to a profile printer. It consists of a diamond point (probe) with a $5 \mu \mathrm{m}$ radius and moves linearly on the working surface. The length examined is $4.0 \mathrm{~mm}$ with a basic span of $0.8 \mathrm{~mm}$. The measured values of $R a$ are within the range 0.05 to $40 \mu \mathrm{m}$ while for $R t$ and $R z$, they lay between 0.3 and $160 \mu \mathrm{m}$. Roughness measurements were directly obtained on the same lathe without disassembling the turned part in order to reduce uncertainties due to operation resumptions [23].

The measurements were repeated 3 times out of 3 positions equally set at $120^{\circ}$ and the result is an average of these values for a given machining pass. The cutting forces in $X, Y$ and $Z$ directions were recorded using a standard quartz dynamometer (Kistler 9257B) allowing measurements from -5 to $5 \mathrm{kN}$. A Rayner 3I infrared pyrometer was used to appraise the temperatures of the chip, part, and cutting tool. This pyrometer is designed to measure temperatures within the range from -30 to $1200{ }^{\circ} \mathrm{C}$. The machining conditions adopted for roughness and cutting forces experiments are depicted in Tables 2 and 3 respectively. For feed rate, depth of cut and cutting speed, the following intervals are used $\left[f: 0.14-0.56 \mathrm{~mm} \cdot \mathrm{rev}^{-1}\right],[a p$ : 2-3 mm] and [ $V c: 34-377 \mathrm{~m} . \mathrm{min}^{-1}$ ] respectively. 

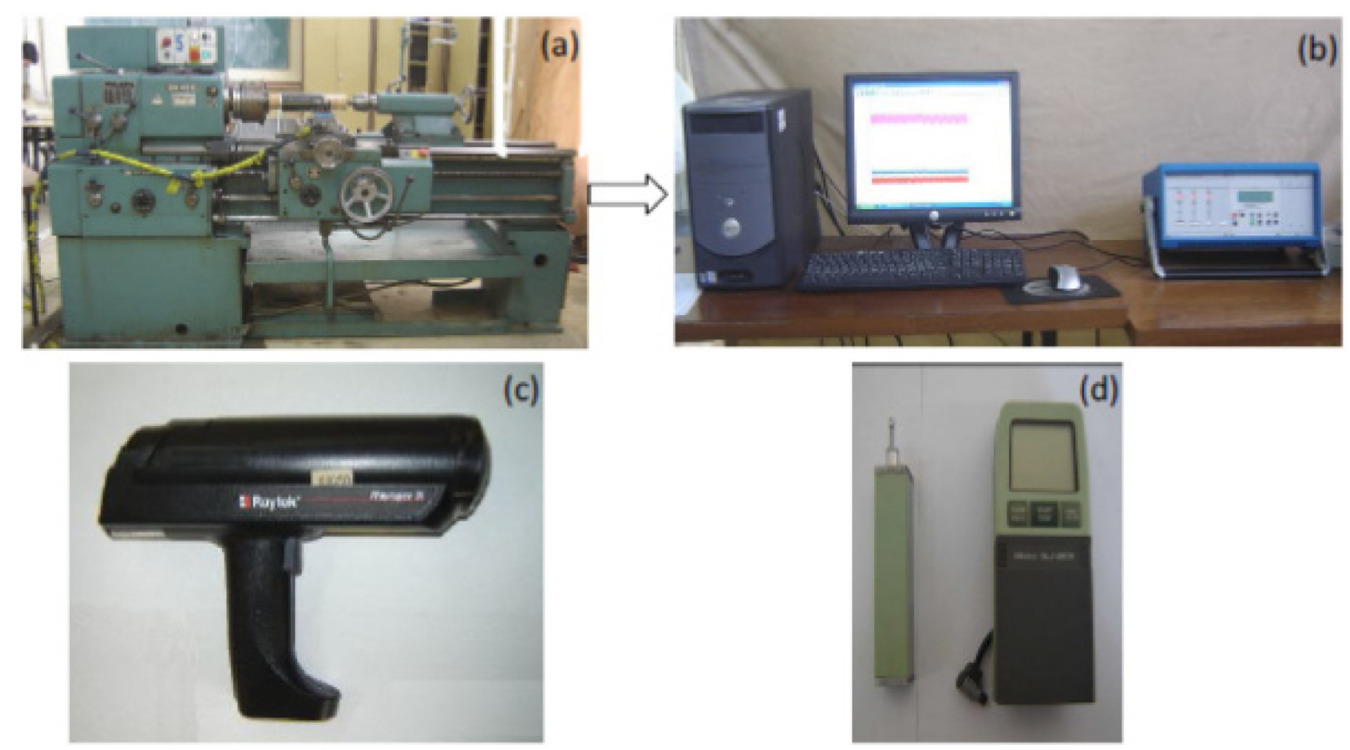

Fig. 1. Experimental setup and measuring devices: (a) cutting forces measurement with piezoelectric dynamometer (Kistler 9257B); (b) charge amplifier and PC with software data acquisition; (c) Rayner 3I infrared pyrometer; (d) surftest 301 Mitutoyo roughness meter.

Table 2. Obtained roughness criteria as a function of the experimental plan.

\begin{tabular}{cccccccccc}
\hline \multirow{2}{*}{ Test $\mathrm{N}^{\circ}$} & \multicolumn{3}{c}{ Variables } & \multicolumn{3}{c}{ HDPE-80 } & \multicolumn{3}{c}{ HDPE-100 } \\
\cline { 2 - 10 } & $V c, \mathrm{~m} \cdot \mathrm{min}^{-1}$ & $f, \mathrm{~mm}_{\mathrm{rev}}{ }^{-1}$ & $a p, \mathrm{~mm}$ & $R a, \mu \mathrm{m}$ & $R z, \mu \mathrm{m}$ & $R t, \mu \mathrm{m}$ & $R a, \mu \mathrm{m}$ & $R z, \mu \mathrm{m}$ & $R t, \mu \mathrm{m}$ \\
\hline 1 & 34 & 0.14 & 2 & 2.82 & 3.12 & 16.39 & 3.02 & 4.08 & 18.44 \\
2 & 34 & 0.36 & 3 & 8.89 & 12.5 & 52.47 & 11.52 & 13.63 & 55.57 \\
3 & 34 & 0.56 & 4 & 11.88 & 16.97 & 84.12 & 14.56 & 18.11 & 85.97 \\
4 & 188 & 0.14 & 3 & 6.11 & 2.21 & 18.13 & 2.29 & 3.25 & 20.25 \\
5 & 188 & 0.36 & 4 & 6.3 & 5.22 & 42.42 & 5.54 & 6.16 & 44.61 \\
6 & 188 & 0.56 & 2 & 8.45 & 10.44 & 69.98 & 9.42 & 11.6 & 72.27 \\
7 & 377 & 0.14 & 4 & 1.67 & 1.68 & 14.95 & 2.68 & 2.75 & 17.14 \\
8 & 377 & 0.36 & 2 & 4.68 & 5.28 & 36.67 & 5.21 & 6.37 & 39.68 \\
9 & 377 & 0.56 & 3 & 8.49 & 8.69 & 44.01 & 8.57 & 9.73 & 47.08 \\
\hline
\end{tabular}

Table 3. Cutting forces components as a function of the experimental plan.

\begin{tabular}{cccccccccc}
\hline \multirow{2}{*}{ Test $\mathrm{N}^{\circ}$} & \multicolumn{3}{c}{ Variables } & \multicolumn{3}{c}{ HDPE-80 } & \multicolumn{3}{c}{ HDPE-100 } \\
\cline { 2 - 9 } & $V c, \mathrm{~m} . \mathrm{min}^{-1}$ & $f, \mathrm{~mm} \cdot \mathrm{rev}^{-1}$ & $a p, \mathrm{~mm}$ & $F a, \mathrm{~N}$ & $F r, \mathrm{~N}$ & $F v, \mathrm{~N}$ & $F a, \mathrm{~N}$ & $F r, \mathrm{~N}$ & $F v, \mathrm{~N}$ \\
\hline 1 & 34 & 0.14 & 2 & 4.43 & 10.75 & 28.75 & 2.56 & 4 & 9.5 \\
2 & 34 & 0.36 & 3 & 11.39 & 24.68 & 74.03 & 6.74 & 5.5 & 23.15 \\
3 & 34 & 0.56 & 4 & 20.02 & 44.3 & 132.89 & 12.12 & 8.5 & 40.01 \\
4 & 188 & 0.14 & 3 & 4.13 & 6.54 & 25.63 & 2.48 & 1.75 & 5.21 \\
5 & 188 & 0.36 & 4 & 13.89 & 30.1 & 90.31 & 8.54 & 3.75 & 29.43 \\
6 & 188 & 0.56 & 2 & 11.52 & 24.98 & 74.93 & 6.88 & 3.25 & 22.35 \\
7 & 377 & 0.14 & 4 & 7.35 & 15.99 & 47.96 & 4.39 & 3.25 & 14.3 \\
8 & 377 & 0.36 & 2 & 8.89 & 19.29 & 57.87 & 5.34 & 3.5 & 14.05 \\
9 & 377 & 0.56 & 3 & 17.08 & 36.81 & 110.43 & 10.28 & 4 & 34.29 \\
\hline
\end{tabular}

\section{Results and discussion}

\subsection{Roughness evolution}

In order to study surface roughness, characterization is limited to the 3 criteria ( $R a, R z$ and $R t$ ). Roughness profiles obtained for different values of feed rate (Fig. 2) show a regular periodicity for feed rate above $0.14 \mathrm{~mm}_{\mathrm{rev}}{ }^{-1}$, while for 0.14 mm.rev ${ }^{-1}$, surface grooves are so small compared to material wrenching; so that profiles lose their periodicity and become rather random. This is confirmed from microscopic observations as shown in (Fig. 3). It is observed that at small feed rates, localized surface tearing takes place while grooving is quite negligible.

Figures 4-6 illustrate the effects of the cutting regime $(V c$, ap and $f$ ) on work-piece roughness. Basically, 


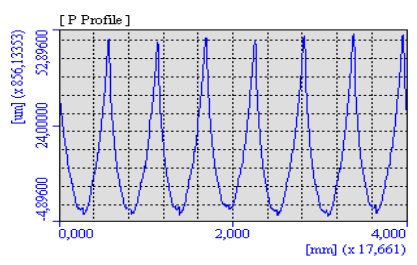

$f=0.56 \mathrm{~mm} / \mathrm{rev}$

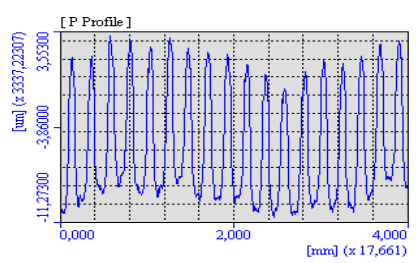

$f=0.22 \mathrm{~mm} / \mathrm{rev}$

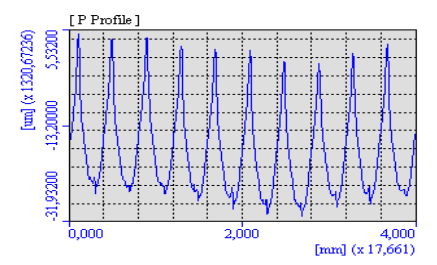

$f=0.40 \mathrm{~mm} / \mathrm{rev}$

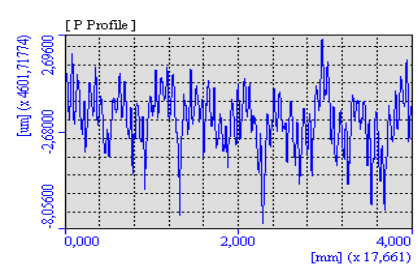

$f=0.14 \mathrm{~mm} / \mathrm{rev}$
Fig. 2. Examples of roughness profiles obtained from the turning HDPE-100 $\left(a p=1 \mathrm{~mm}\right.$ and $\left.V c=118 \mathrm{~m} \cdot \mathrm{min}^{-1}\right)$.

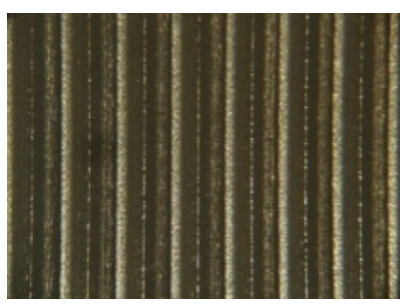

$f=0.56 \mathrm{~mm} / \mathrm{rev}$

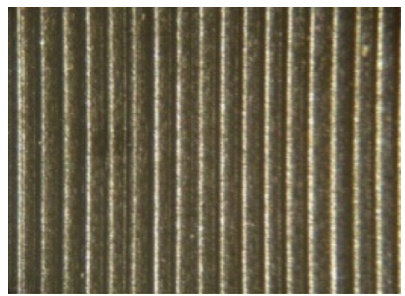

$f=0.22 \mathrm{~mm} / \mathrm{rev}$

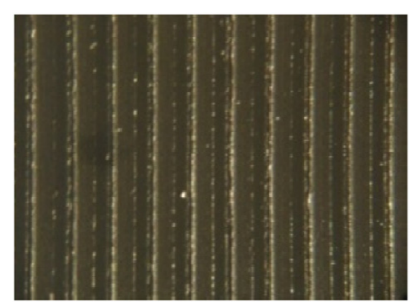

$f=0.40 \mathrm{~mm} / \mathrm{rev}$

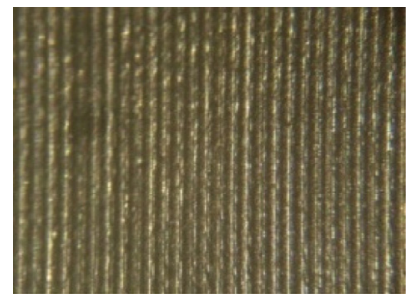

$f=0.14 \mathrm{~mm} / \mathrm{rev}$
Fig. 3. Surface microscopic observations when turning HDPE$100\left(a p=1 \mathrm{~mm}\right.$ and $\left.V c=118 \mathrm{~m} \cdot \mathrm{min}^{-1}\right)$.

increased $V_{c}$ improves the surface quality especially for speeds up to $200 \mathrm{~m} \cdot \mathrm{min}^{-1}$ (Fig. 4). Alternatively, an increase of $f$ or ap deteriorates surface quality with $f$ noted as a determinative factor (Figs. 5 and 6). The generated surface comprises helical furrows resulting from the tool shape and the pattern of tool-part movements. Feed rate effect on surface roughness of high density polyethylene parts is significant such as in the case of crystalline materials [23].

In order to comprehend and control HDPE turning, it is necessary to develop correlations between roughness criteria and cutting parameters, as it has been done for other materials $[23,24]$, in the following form:

$$
R=C_{1} \cdot f^{x_{1}} \cdot a p^{x_{2}} \cdot V c^{x_{3}}
$$

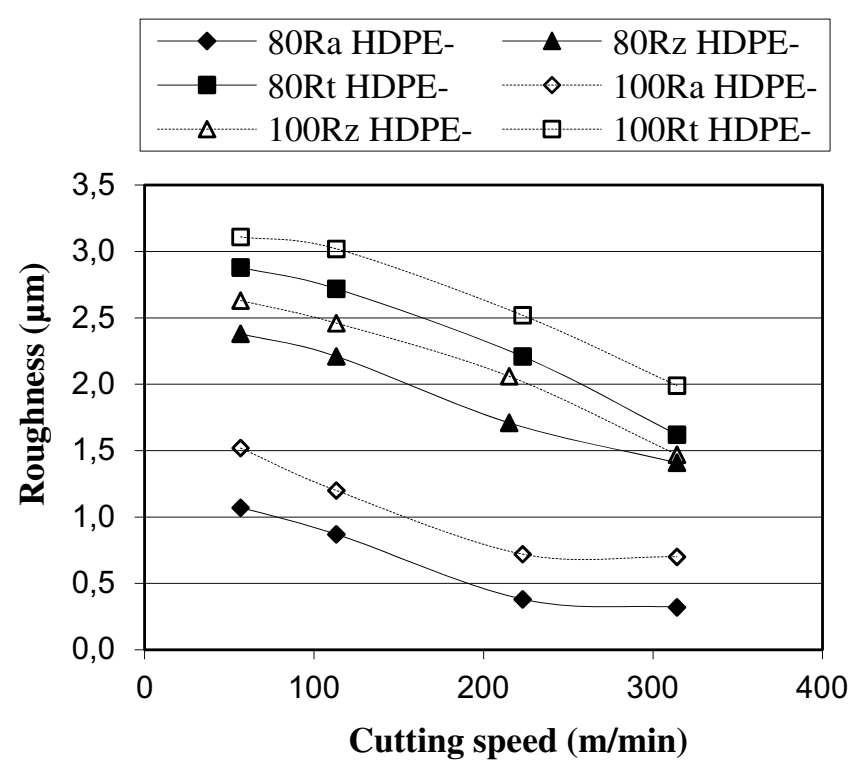

Fig. 4. Cutting speed effect on roughness.

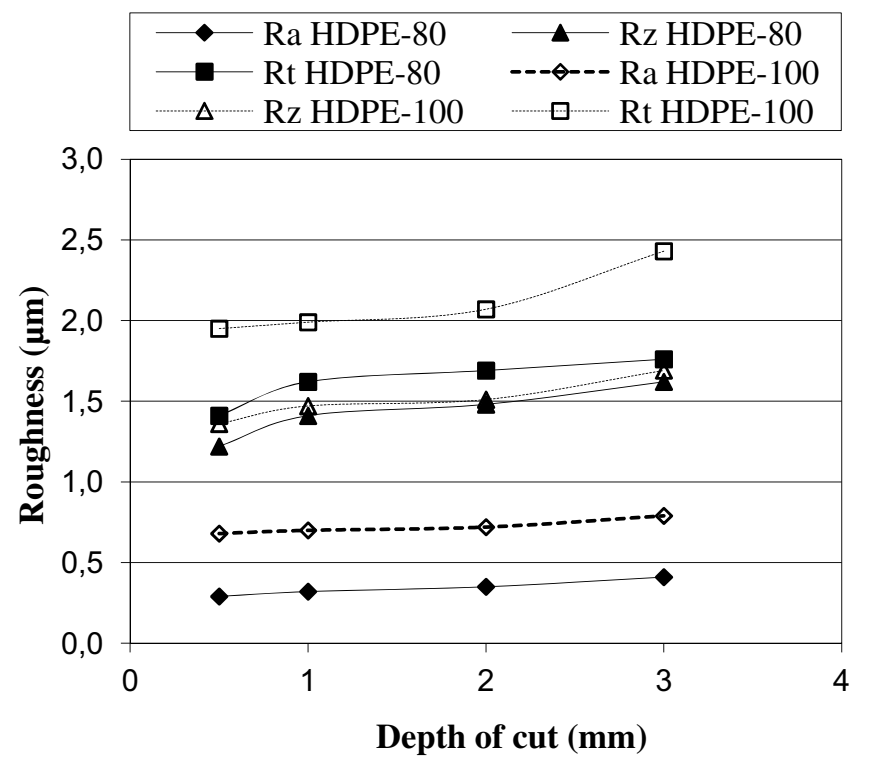

Fig. 5. Depth of cut effect on roughness.

where $C_{1}, x_{1}, x_{2}$ and $x_{3}$ are constants experimentally assessed. Depending on the sign and the value of each exponent $\left(x_{i}\right)$, the importance of each cutting parameter is deduced which helps understanding the basic effect that underlines the optimum machining conditions sought. Using the multifactorial method, constants of the parametric Equation (1) are determined from statistical least square analysis. The following correlations are obtained for HDPE-100:

$$
\begin{aligned}
& R a=e^{3.22} \cdot f^{1.06} \cdot a p^{0.19} \cdot V c^{-0.21} \quad\left(R^{2}=0.94\right) \\
& R z=e^{4.36} \cdot f^{0.96} \cdot a p^{0.03} \cdot V c^{-0.25} \quad\left(R^{2}=0.97\right) \\
& R t=e^{5.25} \cdot f^{0.93} \cdot a p^{0.09} \cdot V c^{-0.12} \quad\left(R^{2}=0.94\right)
\end{aligned}
$$




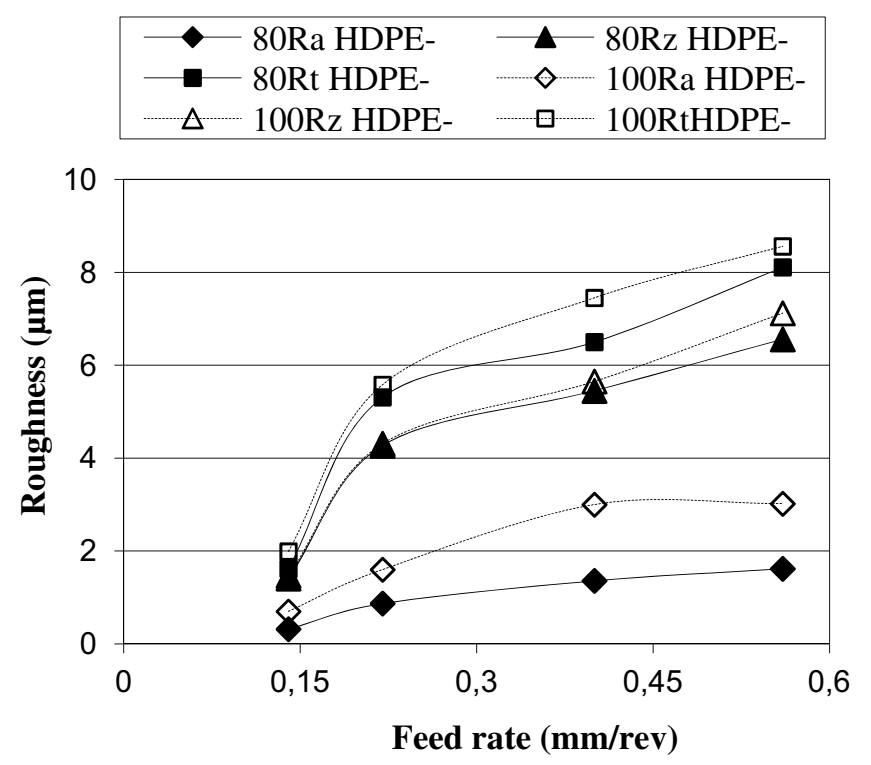

Fig. 6. Feed rate effect on roughness.

and for HDPE-80:

$$
\begin{aligned}
& R a=e^{3.37} \cdot f^{0.81} \cdot a p^{0.12} \cdot V c^{-0.17} \quad\left(R^{2}=0.84\right) \\
& R z=e^{4.65} \cdot f^{1.18} \cdot a p^{0.03} \cdot V c^{-0.30} \quad\left(R^{2}=0.96\right) \\
& R t=e^{5.29} \cdot f^{0.98} \cdot a p^{0.10} \cdot V c^{-0.13} \quad\left(R^{2}=0.94\right)
\end{aligned}
$$

The parametric models represented by Equations (2) to (7) give satisfactory correlations based on experimental results. Results predict roughness criteria obtained by selected cutting conditions. Feed rate is still the dominant factor on roughness criteria as it has been shown for other materials $[23,24]$. Results of roughness experiments (Figs. 4-6 and Tab. 2) show that improved surfaces are obtained during the machining of HDPE-80. This is due to the difference in hardness levels between the two tested materials. Indeed, in Table 1 , the hardness of HDPE-80 between $0{ }^{\circ} \mathrm{C}$ and $40{ }^{\circ} \mathrm{C}$ is higher than that of HDPE100 which allows a better surface finish in the case of HDPE-80. Similar results are found by Xiao and Zhang for HDPE and LDPE (low density PE) as surface roughness decreased with the cutting speed and the increase in shear stress indicates that a greater mechanical strength usually results in a better surface finish when cutting very soft polymers having high molecular segments mobility [9]. Besides that, the rate of increase in shear stress of the softer LDPE is indeed faster than that of the harder HDPE, indicating that the effect of the strain rate on the shear stress depends on the material properties.

Considering the fracture stress and mobility of molecular segments of the two grades of material, the results seem to imply that a too low mechanical strength of a soft polymer prevents a good surface finish. This is understandable if the deformation in the cutting zone is taken into account. In this case, the cutting forces produce plastic deformation on both the cutting surface and its immediate sub-surface, resulting in a rough machining surface. It should be mentioned that if the $T_{\mathrm{g}}$ of a

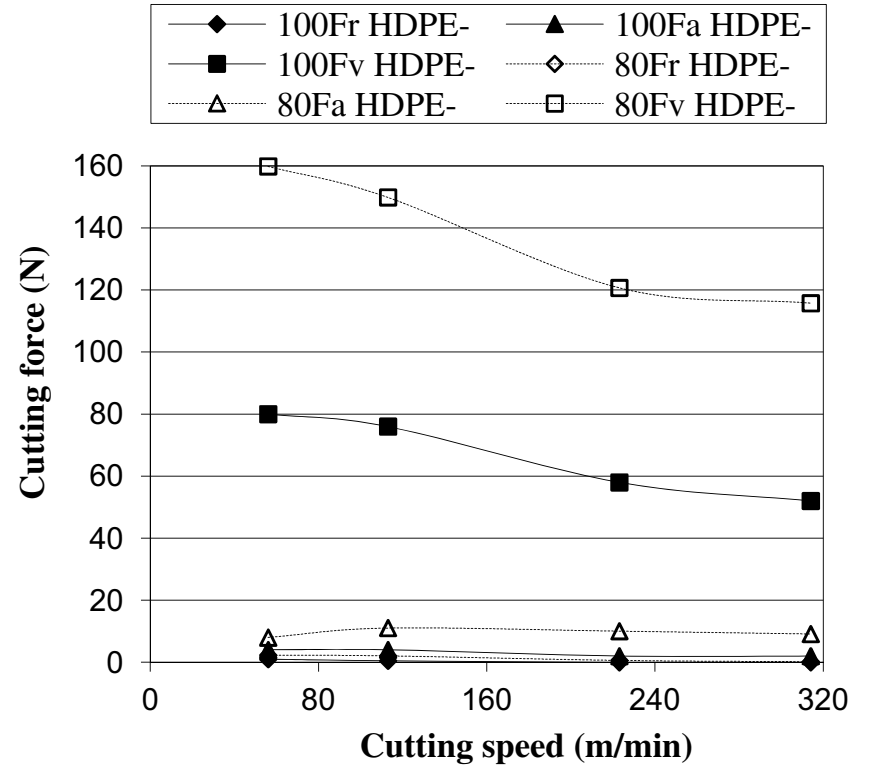

Fig. 7. Cutting speed effect on cutting forces.

polymer is far beyond room temperature and the polymer is quite stiff, the surface finish might be improved when a large long-range mobility of molecular segments and a low mechanical strength are achieved during polymer processing $[6-10,13]$.

\subsection{Cutting forces}

Figures 7-9 illustrate cutting forces evolution according to the material removal process parameters for the present machining system. It is realized that an increase in the cutting speed leads to a gradual decrease of the 3 cutting force components. This is usually due to a temperature rise (more heat is generated) in the cutting zone, which softens the polymer and thus, requires less dissipative forces.

It should be noted that the cutting conditions employed did not favour any material adherence on tool cutting edge. It is observed that the rate of cutting force decrease (especially for $F v$ ) slows down beyond a speed of $200 \mathrm{~m} \cdot \mathrm{min}^{-1}$. It is thus concluded that when turning these two HDPE resins, the tangential force $(F v)$ becomes dominant as compared to the other cutting forces components. The influence of the feed rate $(f)$ and depth of cut $(a p)$ is given in Figures 8 and 9 and it is observed that the cutting forces increase with $f$ and $a p$ since the sheared PE chip section is proportional to feed rate and depth of cut.

The same approach used for roughness characterization can be extended to develop correlations between cutting forces evolution in HDPE turning as a function of cutting regime parameters in the following form:

$$
F=C_{2} \cdot f^{y_{1}} \cdot a p^{y_{2}} \cdot V c^{y_{3}}
$$

where $C_{2}, y_{1}, y_{2}$ and $y_{3}$ are constants experimentally evaluated. Likewise, the sign and the value of each exponent 

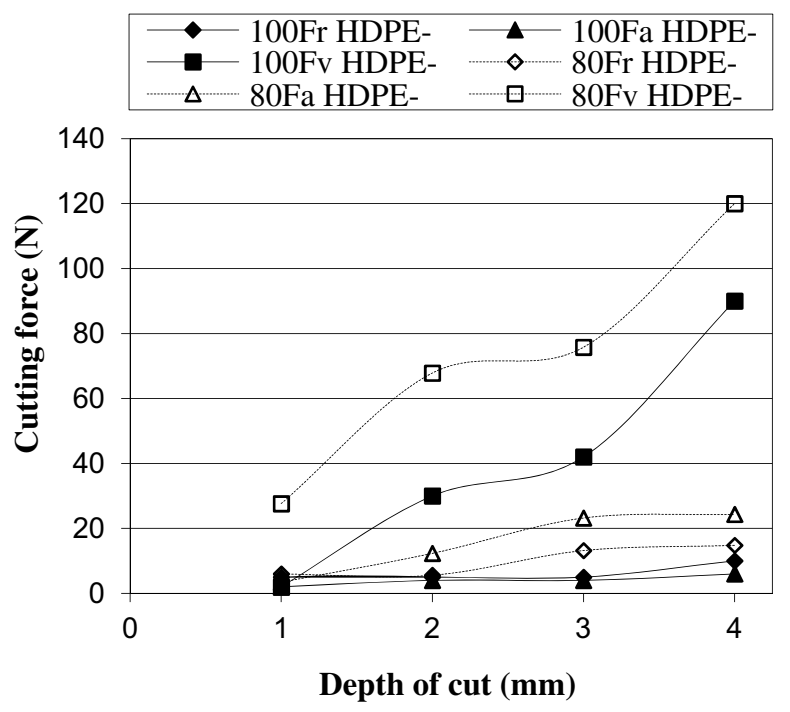

Fig. 8. Depth of cut effect on cutting forces.

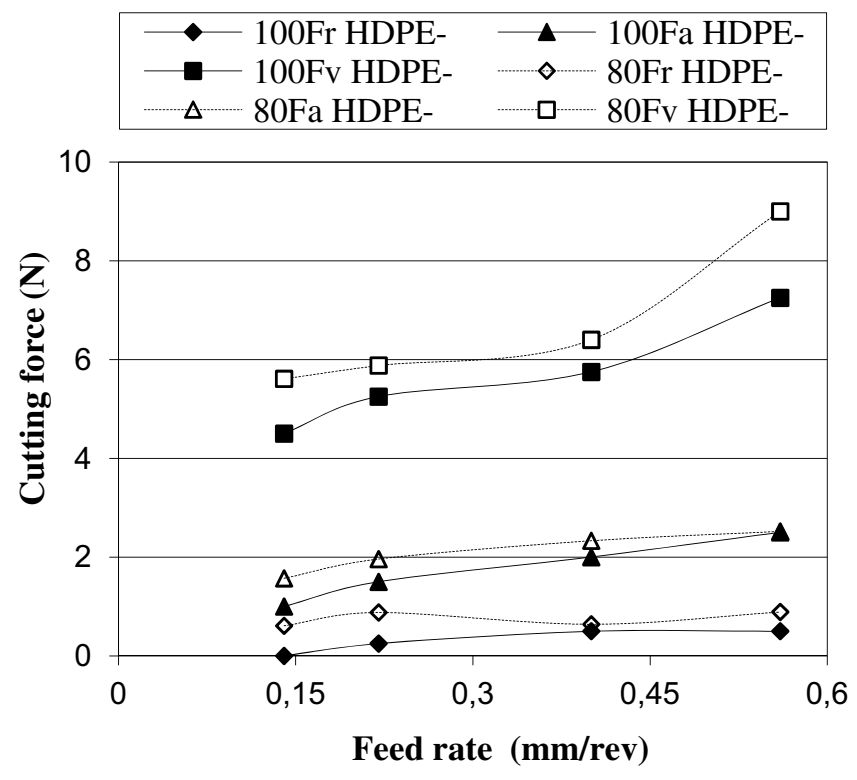

Fig. 9. Feed rate effect on cutting forces.

$\left(y_{i}\right)$ specify the importance of each cutting parameter and enable understanding the basic effect that underlines the optimum machining conditions in terms of forces. Using the multifactorial method, the constants of the parametric Equation (8) are obtained from statistical least square analysis [24]. The following correlations are deduced for HDPE-100:

$$
\begin{aligned}
& F a=e^{1.94} \cdot V c^{-0.003} \cdot f^{0.83} \cdot a p^{0.74} \quad\left(R^{2}=0.98\right) \\
& F r=e^{2.59} \cdot V c^{-0.24} \cdot f^{0.38} \cdot a p^{0.36} \quad\left(R^{2}=0.87\right) \\
& F v=e^{3.44} \cdot V c^{-0.6} \cdot f^{0.91} \cdot a p^{0.80} \quad\left(R^{2}=0.93\right)
\end{aligned}
$$

and for HDPE-80:

$$
\begin{array}{ll}
F a=e^{2.51} \cdot V c^{-0.004} \cdot f^{0.81} \cdot a p^{0.70} & \left(R^{2}=0.98\right) \\
F r=e^{3.55} \cdot V c^{-0.35} \cdot f^{0.87} \cdot a p^{0.64} & \left(R^{2}=0.95\right) \\
F v=e^{4.41} \cdot V c^{-0.01} \cdot f^{0.83} \cdot a p^{0.72} & \left(R^{2}=0.98\right)
\end{array}
$$

The parametric models represented by Equations (9) to (14) give satisfactory correlations based on experimental results obtained at the laboratory scale. Feed rate still is the dominant factor on cutting forces evolution. On the other hand, the classification of the different $\left(y_{i}\right)$ shows that the greatest influence is kept for the feed rate, followed by the depth of cut parameter. Cutting speed gained a relatively small impact in this case.

The cutting forces measured in this study are of the same order of magnitude as those required for the machining of polyetheretherketone (PEEK) composite materials obtained during tests carried out by Mata et al. [25]. In this study, the specific cutting pressure during machining of PEEK composites was investigated. Globally, it was found that, for a given cutting speed, the specific cutting pressure sharply decreases with increase in feed rate in the case of PEEK virgin material. On the other hand, specific cutting pressure is less sensitive to variations of cutting speed for a given feed rate for PEEK composite materials.

\subsection{Cutting zone temperature evolution}

Three sets of unifactorial tests have been developed to investigate the effects of the 3 cutting parameters on temperature evolution in the cutting zone. The results obtained are summarized in Table 4. During machining, it was noted a flow of hot chip, especially for large values of cut depths. It is concluded that value of the depth of cut has a great influence on the cutting temperature. The amount of heat generated is the result of plastic deformation and friction at the interfaces. Cutting temperature is slightly higher during the machining of HDPE- 80 compared to that of HDPE-100. These values are to be considered with caution because of the procedure used; however, they give a worthy indication when comparing machining of the two polymers. This is again explained by the difference in hardness between the two materials (Tab. 1) [5].

Experimental results allowed the determination of mathematical models, expressing the relationship between cutting temperature and cutting parameters. The subsequent correlations are obtained for HDPE-100:

$$
\begin{array}{ll}
t^{\circ}=18.76 \cdot a p^{0.33} & \left(R^{2}=0.72\right) \\
t^{\circ}=11.51 \cdot V c^{0.15} & \left(R^{2}=0.94\right) \\
t^{\circ}=30.76 \cdot f^{0.19} & \left(R^{2}=0.97\right)
\end{array}
$$


Table 4. Measured temperatures in the cutting zone as a function of regime parameters.

\begin{tabular}{|c|c|c|c|c|c|c|c|c|}
\hline \multirow{2}{*}{$V c, \mathrm{~m} \cdot \min ^{-1}$} & \multicolumn{2}{|c|}{$t,{ }^{\circ} \mathrm{C}$} & \multirow{2}{*}{$f, \mathrm{~mm}_{\mathrm{rev}}{ }^{-1}$} & \multicolumn{2}{|c|}{$t,{ }^{\circ} \mathrm{C}$} & \multirow{2}{*}{$a p, \mathrm{~mm}$} & \multicolumn{2}{|c|}{$t,{ }^{\circ} \mathrm{C}$} \\
\hline & PE-100 & PE-80 & & PE-100 & PE-80 & & PE-100 & PE-80 \\
\hline 56 & 21 & 22 & 0.14 & 21 & 22 & 1 & 21 & 22 \\
\hline 113 & 24 & 24 & 0.22 & 23 & 25 & 2 & 23 & 24 \\
\hline 223 & 25 & 27 & 0.40 & 25 & 27 & 4 & 24 & 27 \\
\hline 314 & 28 & 29 & 0.56 & 28 & 30 & 7 & 43 & 43 \\
\hline
\end{tabular}

Table 5. ANOVA model results for roughness data of HDPE-80 and HDPE-100.

\begin{tabular}{ccccccccc}
\hline \multirow{2}{*}{ Response } & \multicolumn{2}{c}{ Sum of squares } & \multicolumn{2}{c}{ Degrees of freedom } & \multicolumn{2}{c}{ Mean square } & \multirow{2}{*}{ F-ratio } \\
\cline { 2 - 7 } HDPE-80 & $R a$ & 2.2344 & 0.8723 & 3 & 5 & 0.7448 & 0.1745 & 4.27 \\
& $R z$ & 5.0371 & 0.0807 & 3 & 5 & 1.6790 & 0.0161 & 104.01 \\
& $R t$ & 3.0965 & 0.1365 & 3 & 5 & 1.0322 & 0.0273 & 37.82 \\
\hline \multirow{3}{*}{ HDPE-100 } & $R a$ & 3.4692 & 0.1356 & 3 & 5 & 1.1564 & 0.0271 & 42.63 \\
& $R z$ & 3.3938 & 0.0955 & 3 & 5 & 1.1313 & 0.0191 & 59.21 \\
& $R t$ & 2.7314 & $0.12 \mathrm{O} 4$ & 3 & 5 & 0.91046 & 0.0236 & 38.61 \\
\hline
\end{tabular}

Table 6. ANOVA model results for cutting force components data of HDPE-80 and HDPE-100.

\begin{tabular}{ccccccccc}
\hline \multirow{2}{*}{ Response } & & \multicolumn{2}{c}{ Sum of squares } & \multicolumn{2}{c}{ Degrees of freedom } & \multicolumn{2}{c}{ Mean square } & \multirow{2}{*}{ F-ratio } \\
\cline { 2 - 8 } & & Regression & Residual & Regression & Residual & Regression & Residual & \\
\hline \multirow{3}{*}{ HDPE-80 } & $F a$ & 2.4592 & 0.0880 & 3 & 5 & 0.81973 & 0.0176 & 46.55 \\
& $F r$ & 1.0632 & 0.3829 & 3 & 5 & 0.35441 & 0.07659 & 4.63 \\
& $F v$ & 2.9778 & 0.4870 & 3 & 5 & 0.9926 & 0.0974 & 10.19 \\
\hline \multirow{3}{*}{ HDPE-100 } & $F a$ & 2.3611 & 0.0961 & 3 & 5 & 0.7870 & 0.0192 & 40.93 \\
& $F r$ & 2.5839 & 0.3608 & 3 & 5 & 0.8613 & 0.0721 & 11.93 \\
& $F v$ & 2.4432 & 0.1204 & 3 & 5 & 0.8144 & 0.0241 & 33.82 \\
\hline
\end{tabular}

Similarly, correlations obtained for HDPE-80 are as follows:

$$
\begin{array}{ll}
t^{\circ}=19.97 \cdot a p^{0.31} & \left(R^{2}=0.78\right) \\
t^{\circ}=11.45 \cdot V c^{0.16} & \left(R^{2}=0.99\right) \\
t^{\circ}=33.49 \cdot f^{0.21} & \left(R^{2}=0.97\right)
\end{array}
$$

The parametric models represented by Equations (15) to (21) give satisfactory correlations based on experimental results, except for those involving $a p$ where $R^{2}$ is close to $80 \%$. This is an interesting indication to define the relative differences between cutting regime parameters that influence the mechanical outputs (roughness and forces) and temperature which describes a complicated localized thermodynamic system. Analysis of the different models indicate that the increase of the chip section represented by the product $(f * a p)$ has the most important influence on cutting temperature. It is noted that the best correlations are obtained with the feed rate $f$.

\section{Mathematical models adequacy}

The analysis of variance (ANOVA) was used to check the adequacy of developed models for a given confidence interval. The ANOVA table consists of sum of squares and degrees of freedom. In order to perform an ANOVA, the sum of squares is usually completed into contributions from regression model and residual error. As for this technique, if the calculated value of $F$-ratio of model is more than the standard tabulated value of table $(F$ table) for a given confidence interval, then the model is adequate within the confidence limit [24-26]. The adequacy of developed mathematical models is presented in Tables 5 and 6 . The model accuracy $(\Delta)$ is commonly given by the following equation:

$$
\Delta=\frac{100}{n} \sum_{i=1}^{n}\left|\frac{y_{i, \exp t}-y_{i, \text { pred }}}{y_{i, \text { pred }}}\right|
$$

where $y_{i, \text { expt }}$ is the measured value of response corresponding to $i$ th trial, $y_{i \text {, pred }}$ is the predicted value of response corresponding to $i$ th trial and $n$ is the number of trials. Equations (2) to (21) are used to test the accuracy of the models using the experimental data. The prediction errors of these models are illustrated in Table 7 together with determination coefficients. It is concluded that the correlations are valid and can be used for predictions when turning both HDPE-80 and HDPE-100. 
Table 7. Percent prediction error of the experimental data and $R^{2}$ values of roughness, cutting force components and cutting zone temperature models of HDPE-80 and HDPE-100.

\begin{tabular}{ccccc}
\hline \multirow{2}{*}{ Response } & \multicolumn{2}{c}{ \% Prediction error of the experimental data } & $R^{2}(\%)$ Values of models \\
\cline { 2 - 5 } & HDPE-80 & HDPE-100 & HDPE-80 & HDPE-100 \\
\hline$R a$ & 22.53 & 9.65 & 84 & 94 \\
$R z$ & 8.14 & 7.91 & 96 & 97 \\
$R t$ & 9.01 & 8.44 & 94 & 94 \\
$F a$ & 7.1 & 6.83 & 98 & 98 \\
$F r$ & 13.35 & 17.12 & 95 & 87 \\
$F v$ & 7.78 & 16.33 & 98 & 93 \\
$t^{\circ}(a p)$ & 10.08 & 12.33 & 78 & 72 \\
$t^{\circ}(V c)$ & 1.05 & 2.25 & 99 & 94 \\
$t^{\circ}(f)$ & 1.69 & 1.50 & 97 & 97 \\
\hline
\end{tabular}

\section{Conclusions}

This study allows drawing some conclusions when machining semi-crystalline PE materials. They are summarized as follow:

(1) Experimental results show that feed rate is the dominant factor on roughness criteria. As a consequence, a better finish surface is obtained for HDPE- 80 resin which is harder than that of HDPE-100. As expected, cutting speed also improves surface quality especially for speeds up to $200 \mathrm{~m} \cdot \mathrm{min}^{-1}$ but unfortunately increases interface temperature which causes surface damage and rapid material softening.

(2) Alternatively, an increase of feed rate or depth of cut deteriorates polyethylene surface, while the generated surface comprises helical grooves resulting from the tool nozzle shape.

(3) An increase in the cutting speed leads to a gradual decrease for the 3 components of the cutting forces $(F r$, $F a$ and $F v)$ and the tangential force $(F v)$ becomes dominant when compared to the other components of cutting forces. Also, it is observed that cutting forces increase with $f$ and $a p$ since the sheared chip section is proportional to feed rate and to depth of cut.

(4) The value of the depth of cut has a great influence on the cutting temperature which is slightly higher during the machining of HDPE- 80 compared to that of HDPE-100.

(5) It is possible to model roughness, cutting forces and cutting zone global temperature as a function of machining regime parameters and the obtained power laws are shown to be valid within the testing intervals. The $\%$ errors and the statistical determination coefficients are within acceptable limits for common quality parameters $\left(R a, F v, t^{\circ}(f)\right)$ for both HDPE resins (for $R a: 8.44 \%<\Delta<9.01 \%, R^{2}>94 \%$, for $F v: 7.78 \%<\Delta<16.33 \%, R^{2}>93 \%$, for $\left.t^{\circ}(f): 1.50 \%<\Delta<1.69 \%, R^{2}>97 \%\right)$. The lower relative errors and the best correlations are obtained for the harder polyethylene (HDPE-80).

Acknowledgements. The authors would like to thank the Sonelgaz Co. of Annaba and the staff of the Technological Hall (Mechanical Engineering Dept., University of Guelma) where the experimental work was completed. They are also grateful to Pr L. Boulanouar (LR3MI, UBM Annaba), Dr. S. Belhadi (LMS, University of Guelma) and the Mechanics of Materials Research team of LR3MI for fruitful discussions.

\section{References}

[1] M. Alauddin, Plastics and their machining: A review, J. Mater. Proc. Technol. 54 (1995) 40-46

[2] P. Gombette, I. Ernoult, Physique des polymères: II. Propriétés mécaniques, Herman Editeurs, Paris, 2005

[3] A.K. Kobayashi, Machining of plastics, Mc Graw-Hill, New York, 1967

[4] A.K. Kobayashi, Machining of plastics: Part II. Modern plastics, New York, 1963

[5] E.F. Smith, Single-point turning of amorphous thermoplastic polymers, MSc, Thesis, North Carolina State University, Raleigh, NC, USA, 1989

[6] J.W. Carr, C. Feger, Ultra precision machining of polymers, Precision Engineering, (Elsevier) 15 (1993) 221-237, http://dx.doi.org/10.1016/ 0141-6359 (93) 90105- J

[7] N. Dusunceli, B. Aydemir, The effects of loading history and manufacturing methods on the mechanical behavior of high density polyethylene, J. Elastomers Plastics 43 (2011) 451-468

[8] S. Humbert, O. Lame, R. Séguéla, G. Vigier, A reexamination of the elastic modulus dependence on crystallinity in semi-crystalline polymers, Polym. 52 (2011) 4899-4909

[9] K.O. Xiao, L.C. Zhang, The role of viscous deformation in the machining of polymers, Int. J. Mech. Sci. (Pergamon), 44 (2002) 2317-2336, www.elsevier.com/ locate/ijmecsci

[10] Q. Jiang, L.C. Zhang, M. Pittolo, The dependence of surface finish of a spectacle polymer upon machining conditions, In: D. Chen et al. Editors, Progress of Machining Technology, Aviation Industry Press, Beijing, 2000, pp. $7-12$

[11] A.E. Young, J.H. Wilson, The critical rake angle in the machining of plastics, Plastics \& Rubber Processing 39 (1978) 77-84

[12] T.J. Vickerstaff, N.Z. Gindy, Orthogonal machining of polymers, Proc. 21st Int. MTDR Conf., Swansea, UK, 1980 
[13] S. Humbert, O. Lame, G. Vigier, Polyethylene yielding behaviour: What is behind the correlation between yield stress and crystallinity? Polym. 50 (2009) 3755-3761

[14] K.-H. Nitta, H. Maeda, Creep behavior of high density polyethylene under a constant true stress, Polym. Test. 29 (2010) 60-65

[15] D. Castagnetti, G.S. Mammano, E. Dragoni, Effect of chlorinated water on the oxidative resistance and the mechanical strength of polyethylene pipes, Polym. Test. 30 (2011) 277-285

[16] J.J. Cheng, M.A. Polak, A. Penlidis, Influence of micromolecular structure on environmental stress cracking resistance of high density polyethylene, Tunnel. Undergr. Space Technol. 26 (2011) 582-593

[17] N. Dusunceli, O.U. Colak, The effects of manufacturing techniques on visco-elastic and visco-plastic behavior of high density polyethylene, Mater. Design 29 (2008) 11171124

[18] STPM Chiali Company, Polyethylene pipes and fittings, Technical Catalog, Sidi Bel-Abbès, Algeria, 2000, www. stpm-chiali.com

[19] K. Chaoui, A. Chudnovsky, A. Moet, Effect of residual stress on crack propagation in MDPE pipes, J. Mater. Sci. 22 (1987) 3873-3879

[20] N. Kiass, R. Khelif, B. Bounamous, A. Amirat, K. Chaoui, Experimental study of mechanical and morphological properties in HDPE-80 gas pipe, Mechanics \& Industry, EDP Sciences, 7 (2006) 423-432, Published online by Cambridge University Press: 2012 http://dx. doi.org/10.1051/meca:2006056
[21] L. Alimi, W. Ghabeche, W. Chaoui, K. Chaoui, Mechanical properties study in extruded HDPE-80 pipe wall used for natural gas distribution, Matériaux \& Techniques 100 (2012) 79-86, http://dx.doi.org/10. $1051 /$ mattech/2012004

[22] C.L. Lin, Use of the Taguchi method and grey relational analysis turning operations with multiple performance characteristics, J. Mater. Manufact. Proc. 19 (2004) 209220

[23] M.-A. Yallese, L. Boulanouar, K. Chaoui, Machining of hardened $100 \mathrm{Cr} 6$ steel using a cubic boron nitride tool, Mechanics \& Industry, (EDP Sci.) 5 (2004) 355-368, Published online by Cambridge University Press: 2012, http://dx.doi.org/10.1051/meca:2004036

[24] B. Fnides, M.-A. Yallese, T. Mabrouki, J.-F. Rigal, Application of response surface methodology for determining cutting force model in turning hardened AISI H11 hot work tool steel, Sadhana, J. Indian Acad. Sci. 36 (2011) 109-123

[25] F. Mata, V.N. Gaitonde, S.R. Karnik, J.P. Davim, Influence of cutting conditions on machinability aspects of PEEK, PEEK CF 30 and PEEK GF 30 composites using PCD tools, J. Mater. Proc. Technol. 209 (2009) 1980-1987, DOI:10.1016/j.jmatprotec.2008.04.060

[26] N. Muthukrishnan, J. Paulo Davimb, Optimization of machining parameters of $\mathrm{Al} / \mathrm{SiC}-\mathrm{MMC}$ with ANOVA and ANN analysis, J. Mater. Proc. Technol. 209 (2009) 225232, www.elsevier.com/locate/jmatprotec 